\title{
Using a Person-Centered Approach in the Instruction of Diverse College Learners with the Aim of Increased Retention and Better Self-Esteem
}

\author{
Anthony Romano* \\ Northern Arizona University, USA
}

*Corresponding Author: Anthony Romano, Northern Arizona University, USA

\begin{abstract}
The purpose of this study was to show how a person-centered approach created by psychologist Carl Rogers, could help diverse students improve college retention and self-esteem. Throughout the report, the term diverse defines learners who are: learning disabled (LD), language two (L2), or multiliterate (different ways of processing information). At the heart of a person-centered approach is a collaborative relationship between the instructor (or teacher, professor, etc.) and the students. This helps with student rapport and creates an atmosphere of trust between the instructor and the students.
\end{abstract}

During the literature review, I discuss the person-centered approach and its tenets. These tenets include empathy, congruence (genuineness) and unconditional positive regard. It is explained that these tenets are needed in the instructor who wishes to practice this approach; all three will create a safe space for diverse students who struggle in many different ways in the classroom environment.

The literature supported that a person-centered approach helps the diverse student population and leads to stronger relationships, better self-esteem and increased retention. I conducted a study of diverse and mainstream students using two surveys called - The Student and Teacher Rapport Inventory (STRI) and The Barrett-Lennard Relationship Inventory (BLRI). In conclusion, the results concurred with my theory and with the literature - a collaborative, person-centered approach in teaching not only helps diverse learners but also mainstream learners.

Lastly, I recommend studying this theory, by using better inventories, perhaps ones with open-ended questions, and to gather a larger student sample across multiple colleges. Additionally, to really narrow down on what individual diverse students need in order to succeed, the future samples need more of that population included in the study rather than a mixed sample.

\section{INTRODUCTION}

Colleges today have an incredibly diverse student body; among them are diverse learners. For the purposes of this study, I will use the term "diverse learners" as anyone who has a learning disability (LD), multiliteracies (ways of processing information differently), language 2 learners (L2) and other diagnoses such as autism and attention deficit disorder (ADD). All of these diverse learners are coming to colleges at an increased rate and face retention issues that some mainstream college students do not. Therefore, it is my professional opinion that with a person-centered approach, an instructor (teacher, professor will also be used interchangeably with this word throughout the paper) can help reach these learners and promote better retention and self-esteem.

The objective of this study was to prove that a person-centered approach, originally coined by Carl Rogers, is very important for diverse learners. There have been studies, that will be covered in this paper that have shown this population is increasing in colleges and enjoys having rapport with their professors. This promotes a safe space for both diverse and mainstream learners, as well as increased self-esteem for them.

Over the last 20 years, there has been an increase of diverse students attending college. According to Ann Orr and Sara Bachman Hammig, one out of 11 high school graduates who identify with having a learning disability (181). Although diverse learners coming to college in increasing numbers is a good thing, there have been issues with this population when it comes to retention. Retention among diverse learners is low due to a variety of reasons and it is important for educators to be able to adequately help these learners to the best of their ability. 
Many times, faculty do not know how to help diverse learners; most of them rely on accommodation recommendations from disability services to aid the diverse learner in reaching success (182). Although accommodations such as extra time to take tests and notetakers (students who take notes for other students who need help), among many other services, are good, they do not always help this population. Research shows that diverse learners appreciate clear goals from their instructors as well as instructor empathy $(187 ; 192)$. This is where Carl Rogers' person-centered approach can be of extreme benefit for the instructor and the student.

A person-centered approach in teaching can be helpful to both the teacher and the student in many ways. For this paper, I will write extensively on why Carl Rogers' theory in education can help with diverse learner student retention. Additionally, I will take a look through a few other theoretical lenses to show that the person-centered approach is applicable and accessible for many educators who have different worldviews and different approaches.

In addition to the literature on instructor support with diverse learners, I conducted my own, study to see how beneficial a person-centered approach is to these learners. These methods will be discussed in the METHOD section of this paper and their results will follow in the RESULTS section of this paper.

\section{THE LITERATURE REVIEW}

\subsection{Carl Rogers and Person-Centered Approach}

In order to fully understand what a person-centered approach is, I will briefly go over its founder and its tenets. Carl Rogers was the creator of the person-centered approach. He was one of the most famous psychologists of the $20^{\text {th }}$ century and developed a theoretical framework to empower the client to seek out his or her own answers to the issues they faced in their daily lives. Unlike Sigmund Freud and other psychoanalysts, Rogers' method of therapy was humanistic; he believed that people could solve their own problems and issues with the counselor/psychologist serving as a facilitator and not as a doctor.

The person-centered approach outlined by Rogers has three tenets - empathy (the ability to put yourself in one's shoes), congruence (genuineness), and unconditional positive regard (no judgement); all of these are core essentials for anyone adhering to the person-centered approach (Rogers 61-2). These tenets help the adherent to self-reflect and move forward with meeting people where they are at. For instance, if an instructor can genuinely empathize with an L2 learner, perhaps because that same instructor may have had a similar background, he or she will be able to understand the struggle of that student in the classroom.

Rogers believed that people could solve their own problems; this sentiment reflects the beliefs of philosopher Giambattista Vico; like Rogers, Vico felt that humans go through a series of changes that are affected by a variety of things in their lives; he strongly believed that the imagination shaped how we respond to many things in life, including other people and cultures. Vico felt that, "human nature and society are not fixed or stationary, but rather in a state of continuous change..." (qtd. in Tateo 49).

\subsection{A Humanist Approach}

Rogers valued empathy, genuineness and a non-judgmental approach towards other people. He believed that this concept would lead to better relationships with others. Rogers wrote, "...when someone understands how it feels and seems to be me, without wanting to analyze me or judge me, then I can blossom and grow..." (62). A person who does not judge but listens can be an effective teacher. This is how one develops rapport with students and this is the heart of what empathy is -- to put oneself in another's shoes. According to Luca Tateo, Vico used a term called fantasia, or the capability to change (49). For Rogers, fantasia would be anyone who was willing to change to improve their situation.

Academically speaking, Rogers felt that his theory could work well in the classroom. Robert Ewen quotes Rogers by saying, "Our schools are more damaging than helpful to personality development, and are a negative influence on creative thinking" (340). There are educators who feel the same way and offer more of a student-centered approach in the classroom, which is less traditional than a standard classroom setting. Paolo Freire remarked that our school system is set up in a way where the 
“...teacher talks and students listen - meekly" (73). He felt that the traditional way of teaching was harming our students, much like Rogers. The student-centered approach disregards the traditional lecture, notes, and presentations and focuses heavily on collaboration between teacher and student (Ahmed 22). This is a path towards better rapport and relationships. As Freire said, "The pursuit of full humanity, however, cannot be carried out in isolation of individualism, but only in fellowship and solidarity" (85).

Person-centered and student-centered teaching philosophies have similar tenets in that they both try to place the teacher and the student on the same field in order to provide a healthier learning environment that is not restrictive for the learner. A person-centered approach, however, can be applied to any approach a teacher has. For instance, if a teacher has a traditional way of teaching, called teacher-approach, he or she can still be person-centered; a person can still be genuine, empathetic and unconditional positive regard for his or her students, no matter what style of teaching they use. Person-centered is very approachable and assessable for all teachers.

\subsection{Instructor Authenticity}

If an instructor follows the tenets of the person-centered approach, he or she will have more empathy and genuineness with his or her students; that is the heart of rapport and that goes a long way with learners who struggle in the classroom. It is an emotional connection that makes relationships work because they are an integral part of learning (Morina 3). This also reflects the existentialist belief about the authentic self. For example, Soren Kierkegaard prioritized values and authenticity in humans (Smith 294). He believed that if an individual (an instructor for the purposes of this paper) embraced authenticity (congruence to Rogers), his or her sense of self would be free to accept responsibility for his or her choices (296). In a sense, authenticity would help the instructor realize his or her own world, thus being able to make a stronger connection with his or her students. Freire commented that "False love, false humility, and feeble faith in others cannot create trust" (91). Looking through this lens of existentialism aligns well with Rogers' tenet of congruence; they both help the individual become authentic and when the students see that authenticity, it enables positive relationship-building in the classroom.

\subsection{Some Myths and Narratives About Diverse Learners}

Over the years there have been several myths about diverse learners that have seeped into the mindset of academics. As an LD learner myself, I have faced many of these narratives as well and they can be remarkably harmful to the educational growth of a student. Psychologist Erik Erikson's Stages of Psychological Development Theory asserts that people are empowered by their environment or repressed by it, which can lead to several maladaptations. Harmful narratives about diverse learners can cause some students to develop these maladaptations that follow them throughout their lifespan, something Erikson wrote and spoke frequently about during his career.

One myth is that LD students have low IQs (Sparks 253). This is not true for all LD learners and can be offensive. It can also be harmful to their development. In stage four of Erikson's Stages of Psychological Development, industry vs inferiority, a student can have both positive and negative experiences with a teacher, a parent, or a peer. In this stage, Erikson argued, the child or student is looking for competency (Kivnick and Wells 42). For the LD learner who encounters the myth that his or her LD must also be accompanied by a low IQ, inferiority or a feeling of incompetence can develop. This can affect later stages according to Erikson and possibly put them on a maladaptive path. Sparks noted that, "...some educators have assumed that such students who are labeled as LD will inevitably have "special difficulties" (qtd. 254). As a result, a maladaptive path for the LD learner due to a negative experience with a teacher can hurt the student causing him or her to withdraw and lose self-confidence.

Another myth is that an L2 learner will have trouble learning a second language at college due to their lack of cognitive ability. That is not always the case either. There is empirical evidence showing that L2 learners can still cognitively learn a new language when compared to other learners (Sparks 256). Again, this myth that L2 learners can be completely unprepared for the difficult challenges in college can create a feeling of incompetence, which is unjust for the learner and can cause lifelong issues with self-confidence. 


\subsection{So Why Focus on This Now?}

There is significant research that has proven that the relationship between the instructor and the student is beneficial for the diverse learner. Morina "identifies a series of elements which help retain students with disabilities at university, including practical curricula which are useful to future professionals; ensuring that learning and teaching enable peer interactions and active engagement; ongoing assessment and feedback; personal tutoring resulting in a close relationship, which in turn enables customized monitoring of each student; and finally, good faculty-student relationships" (qtd. 2).

The longer the issues concerning the diverse student learning populations goes unaddressed the worse it will be. It does not get any more emergent than that. Before we get to some of the changes, I would like to see implemented into a healthy learning environment, I will look at some complaints these students have about many of their instructors. For some diverse learners who have difficulty accessing the work in class, some have stated that their instructors move along with lectures way too fast (Madriaga 652). This is problematic for the diverse learner who may read at a slower pace or the L2 learner who is translating the material from their primary language into English at a slower rate as well. One comment from a student stated: "I have difficulty keeping up with the lecturers...they often speak too quickly and I miss the point I was trying to note down" (653). This is problematic for diverse learners; it can lead to low self-esteem in their abilities to do well in a regular class and may lead to high dropout rates, which is bad all around - both for the college, and most importantly, the student.

Through a Jungian lens, there is the belief that people wear masks. These masks are personas; an example of which is the instructor who appears to care during classes and in lectures, but afterwards does not follow through with helping the students in need. This is what Jung refers to as a public persona - it represents the dark side each of us have (Smith 322). This dark side is not genuine; therefore, it is of no use to the student. Unconditional positive regard would dispel this public persona. To Rogers, this is different than conditional positive regard in which the instructor unconditionally wants to help his or her students, and not a select few (Ewen 329). There is no mask, no public persona with unconditional positive regard.

Rogers' person-centered approach allows the instructor to develop rapport with his or her students. If the student sees that the instructor is genuine and has his or her best interests at heart, a safe classroom environment is created for that learner. According to Morina's research, "When students perceive that faculty listen and show immediacy through their behaviors which generate a sense of closeness, they experience learning more positively, feel emotionally supported and are more likely to express their own emotions in a more authentic manner" (qtd. 3).

\subsection{Student-Centered Approach}

In education there are two other approaches known as teacher-centered and student-centered. First, in a teacher-centered classroom the students have no control over what they learn (Ahmed 22). The head of the class is the instructor and he or she maintains classroom order. Dr. Joseph Lathan explains that teachers in this environment feel safe and comfortable (1). To Lathan, this style is also called, "Sage on the Stage" (2). This is the most traditional way of teaching students; the teacher is at the head of the class and the students are facing the teacher.

Lathan uses the term "empty vessels" as the way the teacher sees his or her students. This is in stark contrast to person-centered. When seeing the students as empty vessels with no individuality (diverse learners as well) there can be no real genuineness between the speaker and the audience. This is where the learning process can break down for students who struggle in these rigid environments. With a teacher-centered approach, learning becomes difficult for diverse learners. If the instructor does not attempt to appeal to his or her audience, the lesson intended to be taught will go over most students' heads (Smith 72). This can lead to "bad practice in teaching" (Madriaga 652).

Like Aristotle, Rogers felt that the teacher should make an effort to appeal to his or her students. If one develops rapport with an audience, that audience will more likely listen to the speaker and truly "hear" what he or she has to say. Genuineness to Rogers is eunoia to Aristotle - a speaker's goodwill for his or her audience (Smith 74). Time has shown educators that the traditional model may not be 
the best as the country has more and more diverse student populations entering schools and colleges. However, to say that the teacher-centered approach is wholly an incorrect way to teach would be ridiculous. The teacher-centered approach has worked well for students for decades (Lathan 2). Still when it comes to specific populations like diverse learners, it may not be the best for them.

To Carl Jung there were archetypes. Thomas Gitz-Johansen stated that, “...the archetypal aspect of the student-teacher relationship, arguing that what he refers to as 'the teacher archetype' must be active in any good teacher who not only aims to transmit information but to stimulate and utilize the teacher-student participation mystique as a means to "nurture the souls of our children"' (qtd. 376-7). There is a term - in loco parentis - which means in place of the parent. Sometimes instructors can be seen as parental or mentor figures to students. To Jung this can also be seen as the Great Mother or Great Father archetypes..." (qtd. 376). Regardless, instructors can have a tremendous impact on a diverse learner's life, especially if the instructor is given the role of the "mother" or "father" archetype.

No matter the archetype, an instructor who utilizes a person-centered approach can easily adopt a student-centered approach with the benefit of creating a collaborative, safe learning environment for diverse and mainstream learners alike. With this approach the instructor does not wield unfiltered power in learning; with a more student-centered approach, an instructor's lecture notes and presentations are abandoned and a more interactive learning style is adopted (Ahmed 22). This is a much more radical approach to teaching - no more is the teacher directly responsible for learning in a traditional sense; he or she takes on the role of a coach and the students play a part in creating the lesson plans (Ahmed 24). This style of instruction is created to help all students play a more active role in how they learn, which can help students with multiliteracies. Some of the methods used in this approach include discussion, role-play and simulation games (Garrett 36).

Student-centered approach seems to be a good fit for students who struggle with learning such as diverse learners. It gives them a chance to use their talents and be creative. This lines up with Vico's philosophy of a holistic approach to understanding and comprehending (Smith 241). Additionally, this approach recognizes that students are diverse and do not learn the same way as other students learn. The one size fits all traditional method is erased with this approach and a new way is adopted for both teacher and student to interact in a modern classroom environment. As mentioned previously, a student's culture may come into the lesson, which can facilitate the learning process. It has been observed that culture plays a very important role in diverse student populations and links them to specific activities (Barton 37).

The student-centered approach is an offshoot of Rogers' person-centered approach; they work well in concert with one another in the classroom and create a strong bond between instructor and student. In both approaches the instructor acts like a coach. Lathan calls this new role of the instructor the "Guide on the Side" (2). Basically, the instructor helps when needed and with the students he or she facilitates the learning process. The person-centered approach would also seek this level of rapport with the students. Person-centered approach agrees with Barton in that "Certain institutions use different literacies to reach others" (43). This approach could very well bridge the gap between the educator and the student in a modern, helping way.

\subsection{Building Meaningful Relationships}

The research overwhelmingly supports rapport between instructors and diverse learners. The benefits help the students become more invested in the class and become more comfortable with an instructor who is flexible and understanding. Rebecca Glazier writes, "If our students feel like they know us and we know them as individual human beings...they are more likely to succeed..." (7-8).

Instructors who use Rogers' person-centered approach often sparks an interest with diverse student learning populations and gives them the confidence they need to overcome obstacles (Morina 11). Glazier comments, "The students in the rapport condition feel like the instructor is engaged and accessible, and this perception translates into measurably better outcomes for students" (20). If a diverse student feels that the instructor, based upon his or her own interactions with said student, is invested in their learning, a sense of closeness will develop. To Vico this is called ingegno, the ability to create a correspondence with things (Tateo 49). Through this lens, instructors and students who build on Rogers' tenets become co-learners, similar to student-centered, which helps diverse learners 
become more engaged in the classroom (Swan et al. 6). The more engaged diverse learner are, the more likely they will have success and stay in school.

\subsection{In Summation}

From the research gathered, a more collaborative, rapport-based relationship between teachers and diverse learners is a great benefit and leads to retention and higher self-esteem. This collaborative relationship can be worked on in many ways, and a person-centered approach, in this writer's opinion, is one of those ways. As a result, I proceeded with my own research into this collaborative relationship that the person-centered approach can deliver. My study and results are in the following two sections.

\section{THE METHOD}

For my study, I decided to use two separate inventories geared to measure whether or not a personentered approach in the classroom would be effective with students. I felt that this method was the most appropriate at this time to test what the literature has proven. Beth Blue Swadener and Kagendo Mutua did state that, "Methodology is important because it frames the questions being asked, determines the set of instruments and methods to be employed and shapes the analysis" (qtd. 4).

The first inventory I used is called The Teacher/Student Rapport Inventory (STRI); this was a survey I created around the tenets of Carl Rogers person-centered approach. All of the questions were multiple choice, yes or no answers. Some sample questions from the STRI were: "I feel comfortable speaking to a teacher I have good rapport with," and "I prefer a teacher who gives us a choice when it comes to major assignments." Both of those questions were some examples of a comfortable, collaborative relationship between the student and the teacher.

The second survey used was called The Barrett-Lennard Relationship Inventory (BLRI); this inventory was a modified version of the original BLRI that was created to measure the personcentered tenets of any individual (Ganley 107; Swan et al. 6). For my classes, I chose certain questions and reworded others to check how important a more person-centered approach in the classroom was to the students. Some questions on the BLRI were: "It is important for my teacher to be genuine - talks to me straight" and "I appreciate it when a teacher shows concern for my academic well-being." Again, these questions as well as the other questions on this inventory were designed to see whether or not the student felt that student and teacher academic relationships were important for their success and retention.

Both inventories were distributed at the beginning of the Spring 2021 semester at Ocean County College across three classes - two Student Success classes and one English Composition II class. Combined, all of the classes had 66 students; of those 66, only 40 participated in the STRI and 34 participated in BLRI. Demographically, there were 19 male participants $(55.8 \%)$ and 15 female participants $(44.1 \%)$ in the BLRI versus the 22 male participants $(55 \%)$ and 18 female participants (45\%) in the STRI. The students had one week to complete each of the forms and they were submitted automatically through Google Forms.

For participating in both inventories, the students were promised extra credit to be used at the end of the semester. This extra credit could be distributed in a variety of ways such as to improve a test score or to make up a missed homework assignment. If those options were not utilized, the extra credit could just be applied to improve their overall percentage at the end of the term. This reward was given to the students as a form of incentive to participate; many students often ask about "extra credit" and "make up assignments" during a term. These inventories would serve to satisfy those concerns and help with this research study.

The inventories were distributed to them via class wide email. Their scores were tallied up as percentages in Google Forms and their identities would be anonymous to each other. The only one who had access to the scores and who answered what questions was me. I purposely did this to see: A) who took the inventories for the extra credit and B) to see what students might need some extra help depending on their answers. Overall, the students were a diverse bunch - there were a few nontraditional students in all of the classes. The average age was 19 years and the oldest age was 52 years. Among the students, there was a mix of diverse learners; these learners had LD with accommodations and some were L2 learners. Of the L2 learners, many were Hispanic and there was one student who spoke Polish as her dominate language. 
There were other diverse learners in the pool of students who had some mental health concerns. Several suffered from anxiety while others suffered from depression; these disclosures came to me via private messages. This is also important to note because mental health is a taboo subject that is often ignored in the classroom but certainly belongs under the umbrella of diverse learners and needs to be noted here.

\section{ReSUlts}

The results of this study were promising and confirmed much of the literature on instructor and teacher rapport - students feel safer and respond better academically to instructors they have rapport with.

In figure 1 of the BLRI, two responses related to instructor and student rapport earned a $100 \%$ "yes" answer. Both of the questions were designed to gauge what students felt about aspects of a personcentered approach, mainly congruence (genuineness). The questions below test a certain level of congruence between the two. The result showed that when the instructor/teacher shows that he or she is honest, down to earth, and invested in the students, it is important for them and their learning.

\section{It is important for my teacher to be genuine - talks to me straight. \\ 34 responses}

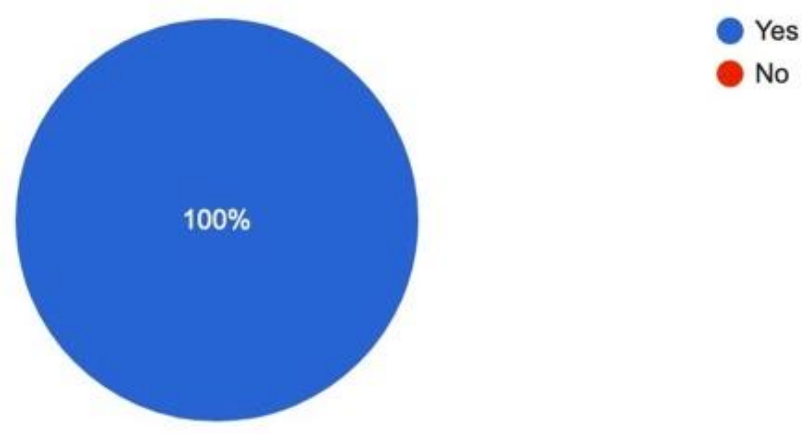

I like it when my teacher makes an effort to help me academically.

34 responses

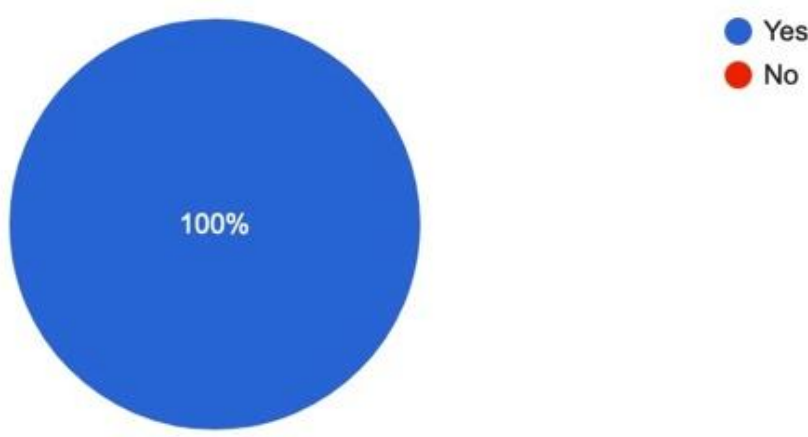

Fig1. BLRI results, congruence

Figure 2 are some samples from the STRI; all 40 participants, which included both diverse and mainstream learners, agree that rapport is important in the classroom. Additionally, in measuring collaboration between students and instructors, $97.5 \%$ of the participants felt that different ways of instruction might be of benefit to them instead of the traditional, teacher-centered approach. A prominent part of a person-centered approach, much like a student-centered approach, is collaboration between the instructor and student; this collaboration involves more discussions in classes as well as creative ways to incorporate assignments (Ahmed 22). 
Using a Person-Centered Approach in the Instruction of Diverse College Learners with the Aim of Increased Retention and Better Self-Esteem

I prefer my teacher to be open to different ways of teaching material and accepting material.
40 responses

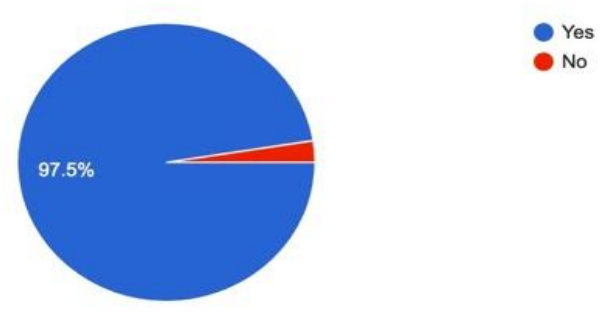

I feel comfortable speaking to a teacher I have good rapport with.

40 responses

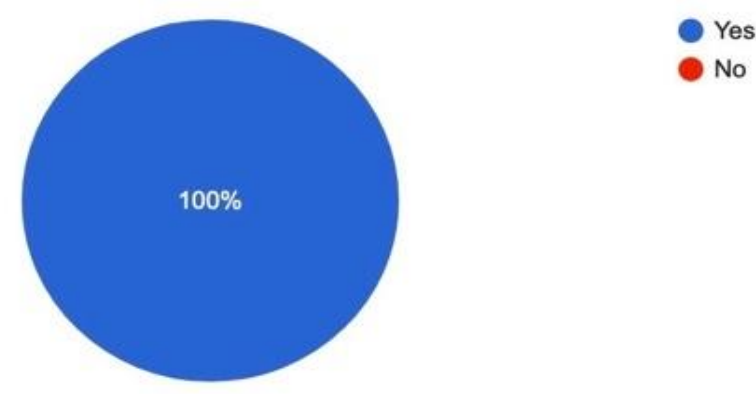

Fig2. STRI results, collaboration/student-centered

Respect was another important aspect covered on both inventories. According to the BLRI results in figure 3, all 34 students felt that respect was important to them and they needed it from their instructors. Respect is a very important part of any relationship and the one within the classroom between an instructor and students is equally important. Also in figure 3, the STRI showed that $80 \%$ of the students believed that instructor and student rapport was very important to their learning.

\section{It is important for my teacher to respect me.}

34 responses

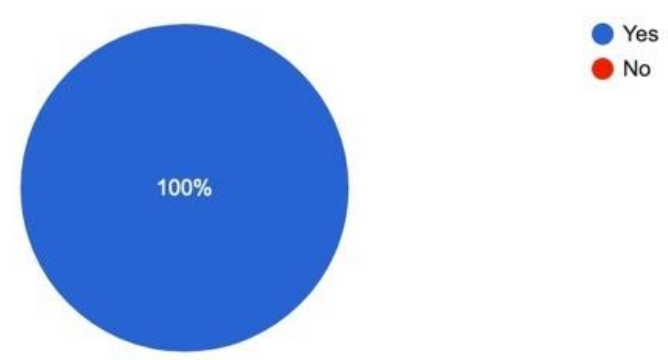

I feel that student/teacher academic relationships are important to my learning.

40 responses

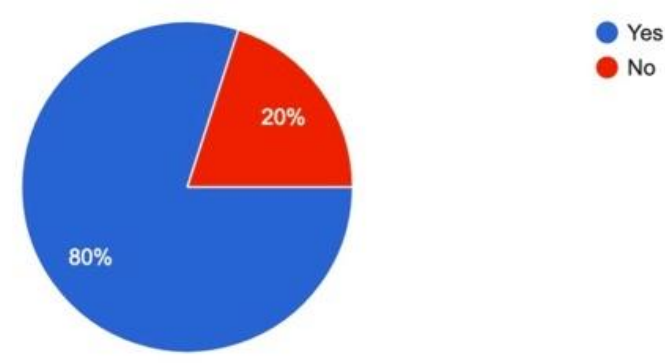

Fig3. BLRI and STRI on respect and mutual relationships 
Although the results provided some validity to my theory and the literature reviewed, there were some questions where the students were more divided. In figure 4, both questions were from the BLRI and surveyed what students felt about self-esteem. The first question involved whether or not students can succeed if they felt their instructor did not think well of them. In the second pie chart, half of the participants felt that they did not matter to their instructors.

If my teacher does not think well of me, I feel like I cannot succeed in class.

34 responses

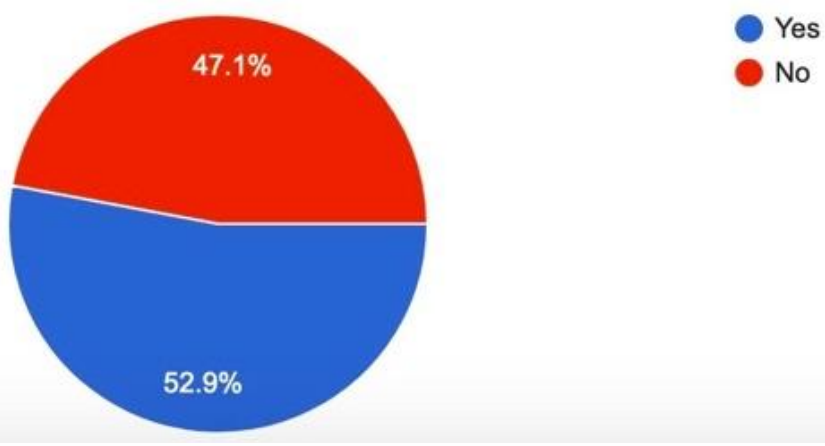

Most of the time, I think I'm just another student and don't matter to teachers.

34 responses

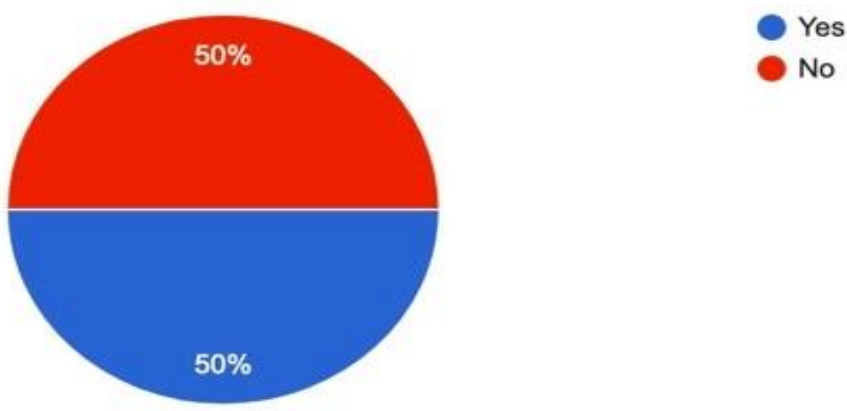

Fig4. BLRI, self-esteem

The alarming results in figure 4 had a deep psychological impact on the students, both diverse and mainstream. According to the results, $47.1 \%$ of the students felt they could not achieve success if their instructor did not think well of them; that could affect student retention for both diverse and mainstream students. With a person-centered approach, the tenets are meant to help the instructor reach diverse learners, as well as mainstream learners, but also empower them to succeed (Ganley 107). If the students who participated in the BLRI have a history of experiencing less success when they feel their instructor does not think well of them, that could have lasting effects on their selfesteem. The aim of a person-centered approach is partially to build self-esteem through rapport with the students.

Also in figure 4, half of the participants felt that they were just another student in the class and they did not matter. Again, this can be related to self-esteem and past experiences with teachers and instructors at various schools. This result should be looked at and studied more closely in the future to see if this feeling of unimportance does relate to retention issues among both student populations.

Figure 5 presented an interesting case; in the STRI, the students preferred an instructor who gave due dates. This question was included in the inventory as a more student-centered question. Although person-centered and student-centered are alike in many ways, a teacher-centered approach can apply person-centered aspects. A tenet of a student-centered approach can involve not having traditional due dates. For this sample of students, they clearly did not like the idea of a teacher who did not give due dates and preferred something more traditional and aligned with a teacher-centered approach. 


\title{
I prefer a teacher who does not give due dates.
}

\author{
40 responses
}

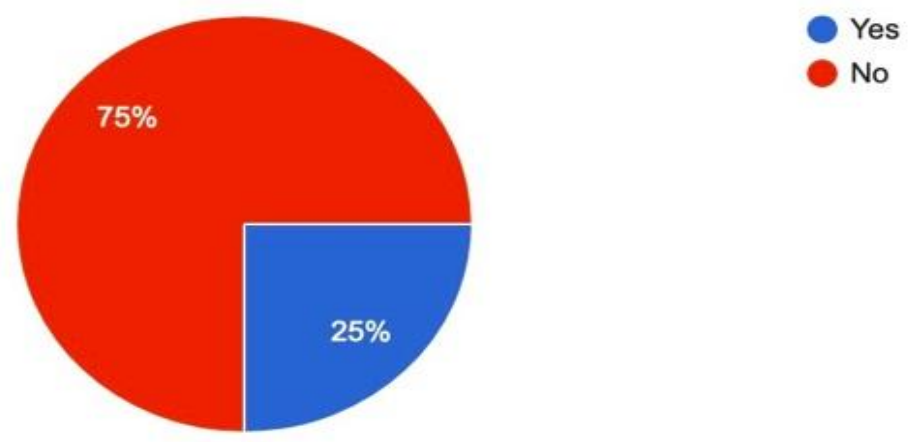

Fig5. STRI, due dates

\section{DISCUSSION}

\subsection{Looking at the Results}

The results of the BLRI and the STRI showed that collaboration and rapport are very important to diverse and mainstream learners. Initially, this study was to show how a person-centered approach can greatly help diverse learners; although diverse learners were indeed part of the sample that participated in both inventories, they were not the majority. Further, looking at the data gathered from the inventories, it showed that even mainstream students value rapport with their instructors, and that relationship can be vital to their academic success.

Figure 4's results were the most interesting. Psychologically speaking, the participants felt that they "didn't matter" to the teacher. Christina Kennedy and Kristine Jolivette state that, "Teacher behaviors toward students can positively or negatively affect behaviors within the classroom setting" (212). Although data for why these students feel the way they do has not been collected, it is something to investigate further, as mentioned in the previous section. In order to successfully reach diverse learners as well as mainstream learners, their backgrounds and experiences need to be considered. For instance, a few of the students struggled with anxiety and depression. For those students who are indeed part of the diverse learner pool, instructors may have to be aware of such things to avoid an incident or exacerbation of anxiety and depression. This is a lot to do, but our population has been changing and these particular students are part of it. To ignore these concerns might lead these students to have further concerns in the future.

Another interesting issue from the results was that even though students seemed to like the collaborative relationship between instructor and student that a person-centered approach can offer, they did not like the idea of no due dates. Figure 5 showed that $75 \%$ of the students who took the STRI preferred due dates. This would seem a bit of a contradiction when it comes to the collaborative relationship between instructor and student that almost uniformly, across both student populations, was felt to be important. What needs to be taken into consideration with this question is that a followed up open-ended response might have brought some clarity. For instance, if the students felt that having an instructor who did not give due dates was not desirable, perhaps they viewed the question as if the instructor gave assignments and then did not give due dates, yet expected the assignments to be done at a specific time that is not addressed. This could create confusion among students, both diverse and mainstream which is how this question might have been interpreted by the sample.

\subsection{Constraints}

The sample population was small. Although the results corresponded with what the literature said when it comes to student and teacher rapport, more students should be included in a future sample. Additionally, out of the 66 students who were in all three classes, only 34 responded to the BLRI and 40 responded to the STRI. 
Another constraint with this study was that it sampled diverse and mainstream learners. The focus of this paper was to see how well diverse learners respond to a person-centered approach. Again, the results showed that diverse learners do respond well to having more rapport and collaboration with their teachers, but their sample across the three classes studied was too small.

The findings of the two inventories showed that both diverse learners and mainstream learners enjoy a certain amount of rapport with their instructors and that they find it important to their learning and retention.

\subsection{On Person-Centered Approach}

It has been said that Rogers person-centered approach is "overly optimistic" (Ewen 341). In order for person-centered education to work on any level, one must be willing to change. For educators who wish to help their students achieve in the classroom, this is a must. Commenting on Rogers's approach, Ewen mentioned that conditional positive regard is when people meet the expectations of others (329). In order for a successful implementation of the person-centered approach, all three of Rogers' tenets must be utilized. That is hard to do for a lot of people, teachers included.

For the instructor to change old methods that are not working when it comes to relationship building, he or she must focus on self-reflection in order to change what needs to be changed. Despite that, there are some instructors who will not be willing to change their ways and this is a constraint in this study. In research conducted by Lopez and Corcoran, it was said that, "...that some teachers were resistant to the ethos of inclusivity and felt the responsibility of 'weaker' students belonged to the special needs team" (6). Further, they found that, "... some teachers worry that their use of time may negatively impact their students" (qtd. 19).

\subsection{Resources for Teachers}

The results of this study showed that a person-centered approach for diverse learners as well as mainstream learners can work and help with rapport and retention. However, teachers can struggle with change and self-reflection just like everyone else. Using a person-centered approach may take some time to learn, focusing on its basic concepts. Workshops can offer some much-needed help. Counseling workshops can provide the instructor with skills he or she may lack and those skills can be applied to their teaching which can benefit a more diverse learning population. Stacy Jacob and Paige Furgerson state, "It is worth your time to read a basic book on counseling techniques so that you may learn how to become a good listener with whom people feel comfortable sharing their stories...learning skills such as attending and reflection coupled with understanding nonverbal behavior help people understand that you are not only listening, but you are also understanding what they say" (8). Many states offer person-centered workshops; in a Covid world, many of these workshops can be completed remotely. Also, some institutions like Rutgers University, offer a variety of workshops throughout the year, person-centered included. Sometimes, educators just have to take a look at their own institution to see what workshops are available.

\section{SECTION V: CONCLUSION}

A person-centered approach to education is very important for both the educator and the student. There are many frameworks that can be utilized effectively when it comes to teaching diverse learners and person-centered has proven to be a non-invasive and easy to pick up approach that has many benefits for the participants. It is important to know that in education, especially when it comes to diverse learners, one size does not fit all; the tenets Rogers laid out in the psychological world have transcended into the educational world with ease. Therefore, a person-centered approach can wield powerful benefits for the instructor and the diverse learning student whose aim is a successful, meaningful future.

We live in an ever-changing world and we have to change with it in order to meet the demands of tomorrow. As educators, we face more and more students entering college and many of them face educational challenges on so many levels. We must face those challenges by adapting to lifelong learning and build bridges with a variety of students in order to achieve student success. 


\section{RECOMMENDATIONS}

For future studies on a person-centered approach for diverse learners, it is recommended that a larger student sample be gathered. The more students surveyed about their feelings towards the approach Rogers proposed so many years ago, the more educators and institutions will get a better understanding of diverse learner needs. As mentioned in the discussion section, this study only sampled a small number of students and not enough diverse learners were included in this sample. Future studies need to correct this to get a more targeted response to the person-centered approach for a diverse population.

Another recommendation is for more schools to be included. For this study, only one school was used - Ocean County College. To get a better idea of diverse learner attitudes towards a person-centered approach, it would be of great benefit to get other schools to participate as well as more inventories used.

My last recommendation involved using different inventories. Although both the BLRI and the STRI were good tools to test rapport and Rogers' tenets, more elaboration on some of the answers could have benefited this study. For instance, the inclusion of open-ended questions rather than "yes" or "no" questions could have cleared up some confusion that the "yes" or "no" questions may have given some of the students.

As a strong believer in the person-centered approach, this writer is convinced that with more studies on instructor and diverse learner rapport and retention, the educational landscape can dramatically change and offer greater success to this population as well as to mainstream students.

\section{APPENDICES}

\section{Appendix A: The Barrett-Lennard Relationship Inventory}

The link to the full survey is included below; some of the inventory's questions and responses have been posted to this document.

Link: https://docs.google.com/forms/d/e/1FAIpQLSdn7fuos17zk1uMwT6qJ95GaFBO5E5n KV4csqu zpteM_se6BQ/viewform?usp=sf_link

Below are some more results that were not covered on the above report, but are still vital to how students feel in the classroom.

\section{My teacher's temperament is important to me.}

\section{4 responses}

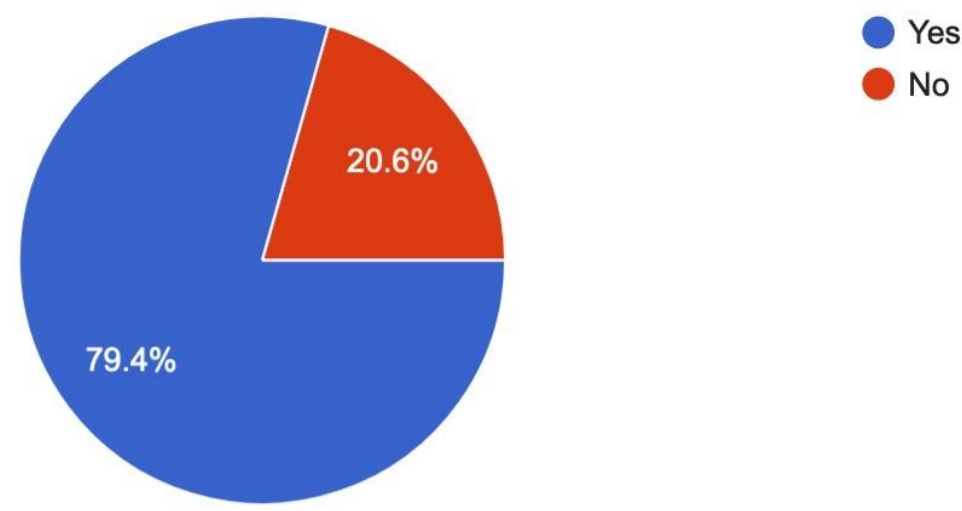

Temperament was an interesting question on the BLRI; almost a quarter (20.6\%) felt that a teacher's temperament was not an issue. Still, that is almost a quarter that does, so that can be an issue for not only diverse learners, but mainstream learners as well. Person-centered approach is designed for the facilitator (teacher in this case) to have a calm demeanor and a good temperament, especially with students who have difficulties in the classroom. 
It is important for my teacher to realize what I mean even when I have trouble saying it.
34 responses

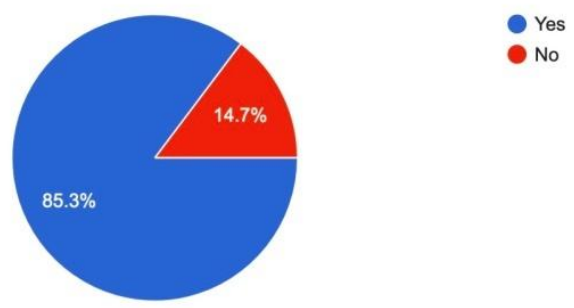

One last example from the BLRI shows that communication is important. Sometimes, especially with diverse learners, students have trouble communicating what issues they are having to the instructor for whatever reason (shy, trouble with speech, etc.). This question was given to see if that could be a major issue for their learning. According to the results, $14.7 \%$ felt it was very important for the teacher to understand what he or she was saying even when it was difficult to communicate. Again, this is something that needs further study.

\section{Appendix B: The Student/Teacher Rapport Inventory}

Below is the link to the Student/Teacher Rapport Inventory. Like with the BLRI, there are some more questions that were not mentioned on the above report, but have meaning to the students in the classroom and for a person-centered approach.

Link: $\quad$ https://docs.google.com/forms/d/e/1FAIpQLScGSBK2lvxvWguoXwrFKDGEwZENC GzKwnIT-r-vWkD0dVbwNg/viewform?usp=sf_link
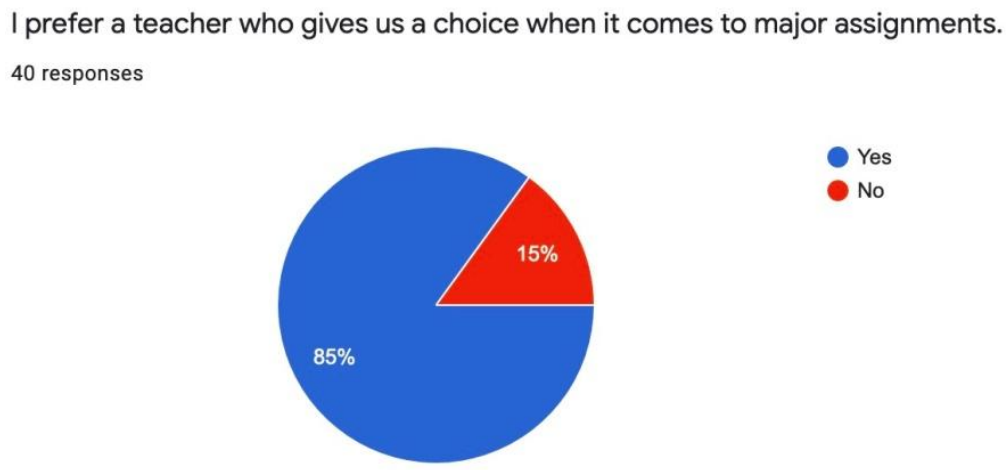

One of the main tenets of a student-centered approach is giving students more of a choice when it comes to assignments. Although $85 \%$ of the student's surveys would have liked more choice, there was still a small number who did not; therefore, I am unsure of having a complete student-centered approach is appropriate if the goal of changing a style is to try and reach as many students as possible. This is why I often explain the differences between a person-centered approach and a student-centered approach. Although similar, a person-centered approach differs from a student-centered approach in that it can work with a traditional teaching setting where the latter does not.

It is important to have a set number of goals for the term to help me learn.

40 responses

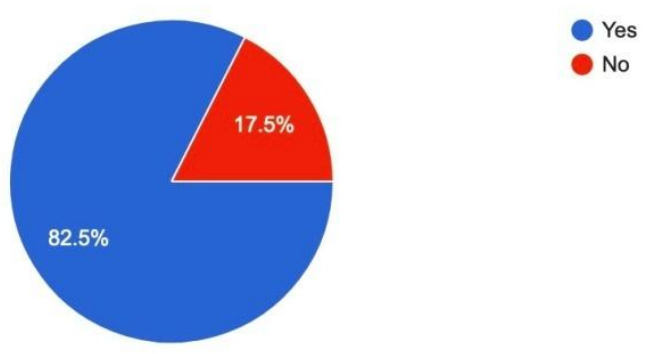


Again, most students prefer to have set goals in a classroom. The above question shows that only $17.5 \%$ of students do not prefer set goals; perhaps they like a more open class environment for learning. This is something that needs to be studied further to get a better understood $\mathrm{g}$ of goal setting in the classroom.

\section{It is important for my teacher to take time and summarize what we learn each day.}

40 responses

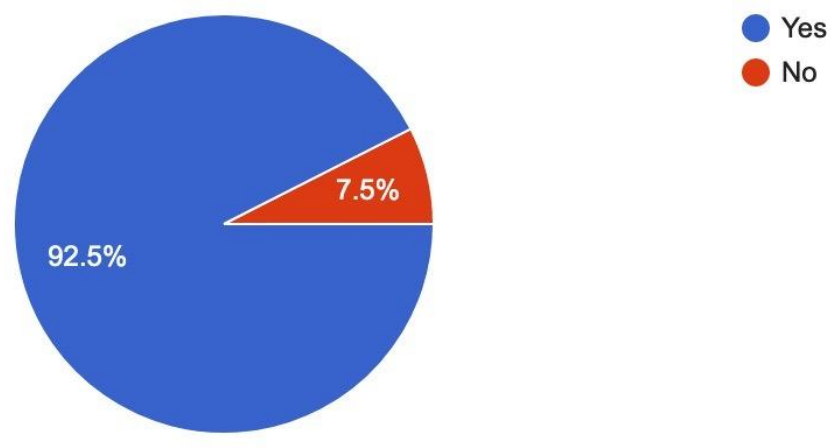

This was an interesting result; most students felt that in order to have a level of success in the classroom, the instructor must summarize what they had learned before a test or some other assignment. Since this sample was a mix of diverse learners as well as mainstream learners, this proves, at least for this sample, that both appreciate and want the instructor to make an effort and go over important things again to create a better understanding of the material. This is something that should be considered by instructors who do not practice this in the future

\section{WORKS CITED}

[1] Ahmed, Ahmed. "Teacher-Centered Versus Learner-Centered Teaching Style." Journal of Global Business Management, vol. 9, no.1, 2013, pp. 22-32.

[2] Barton, David, Literacy: An Introduction to the Ecology of Written Language. Blackwell Publishing, 1994.

[3] Ewen, Robert. An Introduction to Theories of Personality, Academic Press, 1980.

[4] Freire, Paolo. Pedagogy of the Oppressed. $30^{\text {th }}$ Anniversary ed., Continuum, 2000.

[5] Ganley, Richard M. "The Barrett-Lennard Relationship Inventory (BLRI): Current and Potential Uses with Family Systems," Family Process, 1989.

[6] Garrett, Tracey, "Student-Centered and Teacher-Centered Classroom Management: A Case Study of Three Elementary Teachers. Journal of Classroom Interaction, vol. 43, no. 1, 2008, pp. 34-47.

[7] Gitz-Johansen, Thomas. "Jung in Education: A Review of Historical and Contemporary Contributions from Analytical Psychology to the Field of Education." The Society of Analytical Psychology, vol. 61, no. 3, 2016, pp. 365-384.

[8] Glazier, Rebecca A., "Building Rapport to Improve Retention in Online Classes." Journal of Political Science Education." vol. 12, no. 4, 2016, pp. 1-30.

[9] Jacob, Stacy. A., \& S. Paige Furgerson. "Writing Interview Protocols and Conducting Interviews: Tips for Students New to the Field of Qualitative Research". Qualitative Report, vol. 17, no. 42, 1-10. 2012.

[10] Kennedy, Christina and Kristine Jolivette. "The Effects of Positive Reinforcement on the Time Spent Outside the Classroom for Students with Emotional and Behavioral Disorders in a Residential Setting." Behavioral Disorders, vol.33, no.4, 2008, pp. 211-221.

[11] Kivnick, Helen Q. and Courtney K. Wells. "Untapped Richness in Erik H. Erikson's Rootstock." The Gerontologist, vol. 54, no. 1, 2013, pp.40-50.

[12] Lathan, Joseph. "Complete Guide to Teacher-Centered vs. Student-Centered Learning. https://onlined egrees.sandiego.edu/teacher-centered-vs-student-centered-learning/

[13] Lopez, Chevon, and Tim Corcoran. "Relationships with Special Needs Students: Exploring Primary Teachers' Descriptions." International Journal of Inclusion. vol. 18, no. 12, 2014, pp. 1-38.

[14] Madriaga, Manuel, et al. "Confronting Similar Challenges? Disabled and Non-Disabled Students' Learning and Assessment Experiences." Studies in Higher Education, vol. 35, no. 6, 2010, pp. 647-658. 
[15] Morina, Anabel. "The Keys to Learning for University Students with Disabilities: Motivation Emotion and Faculty-Student Relationships.” PLOS ONE, vol. 14, no. 5. 2019.

[16] Orr, Ann C. and Sara Bachman Hammig. "Inclusive Postsecondary Strategies for Teaching Students with Learning Disabilities: A Review of the Literature.” Learning Disability Quarterly, vol. 32, 2009, pp. 181195.

[17] Rogers, Carl R. On Becoming a Person. Houghton Mifflin Company, 1961.

[18] Smith, Craig R. Rhetoric and Human Consciousness, Waveland Press, $5^{\text {th }}$ Ed., 2017.

[19] Sparks, Richard L. "Myths About Foreign Language Learning and Learning Disabilities." Foreign Language Annals, vol. 49, no. 2, 2016, pp. 252-270.

[20] Swadener, Beth Blue, and Kagendo Mutua. "Decolonizing Performances: Deconstructing the Global Postcolonial." Handbook of Critical and Indigenous Methodologies, edited by Norman K. Denzin at al., SAGE, 2008, pp. 31-45.

[21] Swan, Karen et al. "Relationships between Carl Rogers' Person-Centered Education and the Community of Inquiry Framework: A Preliminary Exploration.” Online Learning Journal, vol.24, no.3, pp.1-15.

[22] Tateo, Luca. "Giambattista Vico and the Principles of Cultural Psychology: A Programmatic Retrospective." History of Human Sciences, vol. 28, no. 1, 2014, pp. 44-65.

Citation: Anthony Romano. "Using a Person-Centered Approach in the Instruction of Diverse College Learners with the Aim of Increased Retention and Better Self-Esteem" International Journal of Humanities Social Sciences and Education (IJHSSE), vol 8, no. 5, 2021, pp. 49-63. doi: https://doi.org/10.20431/23490381.0805007.

Copyright: (c) 2021 Authors. This is an open-access article distributed under the terms of the Creative Commons Attribution License, which permits unrestricted use, distribution, and reproduction in any medium, provided the original author and source are credited. 